\title{
Modifikasi Metode Iterasi Dua Langkah Menggunakan Kombinasi Linear Tiga Parameter Real
}

\author{
Alfi Husni ${ }^{1}$, Wartono ${ }^{2}$ \\ 1,2Program Studi Matematika, UIN Sultan Syarif Kasim Riau, Jl. Subrantas, Pekanbaru, \\ Indonesia; ${ }^{1}$ alfi.husni0@gmail.com, ${ }^{2}$ wartono@uin-suska.ac.id
}

\begin{abstract}
Abstrak
Artikel ini membahas modifikasi metode iterasi dua langkah dengan menggunakan kombinasi linier tiga parameter dan tiga metode iterasi berorde konvergensi tiga yang masing-masing dihasilkan dari penjumlahan metode Potra-Ptak dan metode varian Newton, modifikasi metode varian Newton rata-rata kontra harmonik, dan Metode Newton-Steffensen. Berdasarkan hasil kajian diperoleh bahwa metode iterasi baru memiliki orde konvergensi empat untuk $\theta 1=-2, \theta 2=3-\theta 3$ dan $\theta 3 \in \mathfrak{R}$ yang melibatkan tiga evaluasi fungsi dengan indeks efisiensi sebesar $4^{1 / 3} \approx 1,5874$. Simulasi numerik diberikan untuk menunjukkan performa metode iterasi baru dibandingkan dengan metode Newton, metode Potra-Ptak, dan metode Chebyshev.
\end{abstract}

Kata Kunci. Indeks efisiensi, metode Newton, metode Potra-Ptak, metode NewtonSteffensen, orde konvergensi.

\section{Pendahuluan}

Persamaan nonlinear merupakan representasi matematis dari persoalan nyata bidang sains dan tehnik. Hampir sebagian besar persamaan nonlinear muncul dalam bentuk persamaan matematika yang cukup rumit dan kompleks, sehingga penyelesaian analitik sering tidak mampu menemukan solusi dari persamaan nonlinear tersebut. Oleh karena itu, penyelesaian alternatif yang digunakan adalah penyelesaian numeris berupa perhitungan komputasi yang dilakukan secara berulang. Penyelesaian persamaan nonlinear dimaksud dalam bentuk

$$
f(x)=0 \text {. }
$$

Salah satu metode iterasi yang sering digunakan untuk menyelesaikan persamaan nonlinear (1) adalah metode Newton dengan bentuk iterasi 


$$
x_{n+1}=x_{n}-\frac{f\left(x_{n}\right)}{f^{\prime}\left(x_{n}\right)}, n=0,1,2,3, \ldots .
$$

Metode Newton konvergen secara kuadratik dan melibaktkan dua evaluasi fungsi dengan indeks efisiensi sebesar 1,4142.

Beberapa peneliti mengembangkan metode iterasi dengan orde konvergensi tiga menggunakan skema langkah kedua, sebagaimana yang dilakukan oleh Potra-Ptak (1984) dan Sharma (2005) yang masing-masing diberikan oleh

$$
x_{n+1}=x_{n}-\frac{f\left(x_{n}\right)}{f^{\prime}\left(x_{n}\right)}-\frac{f\left(y_{n}\right)}{f^{\prime}\left(x_{n}\right)}
$$

dan

$$
x_{n+1}=x_{n}-\frac{f\left(x_{n}\right)^{2}}{f^{\prime}\left(x_{n}\right)\left(f\left(x_{n}\right)-f\left(y_{n}\right)\right)}
$$

dengan $y_{\mathrm{n}}$ didefinisikan oleh (2).

Selanjutnya Chun (2006) juga melakukan pengembangan terhadap metode Newton dengan menggunakan metode analisis homotopi dengan orde konvergensi tiga sebagai berikut:

$$
x_{n+1}=x_{n}-\frac{f\left(x_{n}\right)}{f^{\prime}\left(x_{n}\right)}-\frac{2 f\left(y_{n}\right)}{f^{\prime}\left(x_{n}\right)+f^{\prime}\left(y_{n}\right)}
$$

dan

$$
x_{n+1}=x_{n}-\frac{f\left(x_{n}\right)}{f^{\prime}\left(x_{n}\right)}-\frac{f\left(x_{n}\right) f\left(y_{n}\right)}{\left(f\left(x_{n}\right)-f\left(y_{n}\right)\right) f^{\prime}\left(x_{n}\right)} .
$$

Metode iterasi yang dikemukaan pada persamaan (3) - (6) merupakan metode iterasdi dengan orde konvergensi tiga. Oleh karena itu, pada makalah ini dilakukan improvisasi orde konvergensi tanpa menambah evaluasi fungsi, sehingga metode iterasi menjadi optimal (Kung dan Traub (1974)).

Oleh karena itu, pada artikel ini akan dikontruksi metode iterasi dua langkah dengan menggunakan penjumlahan secara linear persaman (3) - (6) dengan melibatkan tiga parameter real $\theta_{1}, \theta_{2}$ dan $\theta_{3}$.

Pada bagian akhir, diberikan simulasi numerik untuk menguji performa metode iterasi yang diusulkan kemudian dibandingkan dengan metode 
iterasi lainnya, seperti: metode Newton, metode Potra-Ptak, dan metode Chebyshev.

\section{Hasil dan Pembahasan}

\subsection{Metode Iterasi yang Dikembangkan}

Pada bagian ini membahas metode iterasi dua langkah yang merupkan hasil penjumlahan linear dari tiga metode baru. Untuk menentukan metode pertama, perhatikan kembali metode Potra-Ptak dan metode varian Newton

$$
x_{n+1}=x_{n}-\frac{f\left(x_{n}\right)}{f^{\prime}\left(x_{n}\right)}-\frac{f\left(y_{n}\right)}{f^{\prime}\left(x_{n}\right)}
$$

dan

$$
x_{n+1}=x_{n}-\frac{f\left(x_{n}\right)}{f^{\prime}\left(x_{n}\right)}-\frac{f\left(x_{n}\right) f\left(y_{n}\right)}{\left(f\left(x_{n}\right)-f\left(y_{n}\right)\right) f^{\prime}\left(x_{n}\right)}
$$

Kemudian Persamaan (7) dan Persamaan (8) dijumlahkan dengan bentuk sebagai berikut

$$
2\left(x_{n+1}\right)=\left(x_{n}-\frac{f\left(x_{n}\right)}{f^{\prime}\left(x_{n}\right)}-\frac{f\left(y_{n}\right)}{f^{\prime}\left(x_{n}\right)}\right)+\left(x_{n}-\frac{f\left(x_{n}\right)}{f^{\prime}\left(x_{n}\right)}-\frac{f\left(x_{n}\right) f\left(y_{n}\right)}{\left(f\left(x_{n}\right)-f\left(y_{n}\right)\right) f^{\prime}\left(x_{n}\right)}\right)
$$

atau

$$
x_{n+1}=x_{n}-\frac{2 f\left(x_{n}\right)+f\left(y_{n}\right)}{2 f^{\prime}\left(x_{n}\right)}-\frac{1}{2} \frac{f\left(x_{n}\right) f\left(y_{n}\right)}{\left(f\left(x_{n}\right)-f\left(y_{n}\right)\right) f^{\prime}\left(x_{n}\right)} .
$$

Selanjutnya, untuk menentukan metode kedua, dilakukan dengan memodifikasi metode varian Newton dengan menggunakan rata-rata kontra harmonik dalam bentuk

$$
x_{n+1}=x_{n}-\frac{f\left(x_{n}\right)}{f^{\prime}\left(x_{n}\right)}-\frac{2 f\left(y_{n}\right)}{f^{\prime}\left(x_{n}\right)+f^{\prime}\left(y_{n}\right)} .
$$

Persamaan (11) dapat ditulis dalam bentuk

$$
x_{n+1}=x_{n}-\frac{f\left(x_{n}\right)}{f^{\prime}\left(x_{n}\right)}-\frac{f\left(y_{n}\right)}{\frac{f^{\prime}\left(x_{n}\right)+f^{\prime}\left(y_{n}\right)}{2}}
$$


Bentuk aritmetika $\frac{f^{\prime}\left(x_{n}\right)+f^{\prime}\left(y_{n}\right)}{2}$ diganti dengan bentuk rata-rata kontra harmonik $\frac{f^{\prime}\left(x_{n}\right)^{2}+f^{\prime}\left(y_{n}\right)^{2}}{f^{\prime}\left(x_{n}\right)+f^{\prime}\left(y_{n}\right)}$, sehingga persamaan (12) dapat ditulis kembali sebagai

$$
x_{n+1}=x_{n}-\frac{f\left(x_{n}\right)}{f^{\prime}\left(x_{n}\right)}-\frac{f\left(y_{n}\right)\left(f^{\prime}\left(x_{n}\right)+f^{\prime}\left(y_{n}\right)\right)}{f^{\prime}\left(x_{n}\right)^{2}+f^{\prime}\left(y_{n}\right)^{2}} .
$$

Persamaan (13) melibatkan empat evaluasi fungsi, yaitu $f(x), f^{\prime}(x n), f(y n)$ dan $\mathrm{f}^{\prime}(\mathrm{yn})$. Oleh karena itu, untuk mengurangi penggunaan evaluasi fungsi pada Persamaan (13), maka $f^{\prime}(y \mathrm{n})$ diaproksimasikan dengan menggunakan hasil penyetaraan metode Homeir dan Steffensen sebagaimana yang dilakukan oleh Chun (2008) dengan bentuk

$$
f^{\prime}\left(y_{n}\right)=\frac{f^{\prime}\left(x_{n}\right)\left(f\left(x_{n}\right)-f\left(y_{n}\right)\right)}{f\left(x_{n}\right)-f\left(y_{n}\right)} .
$$

Selanjutnya dengan mensubstitusikan Persamaan (14) ke Persamaan (13), diperoleh

$$
x_{n+1}=x_{n}-\frac{f\left(x_{n}\right)}{f^{\prime}\left(x_{n}\right)}-\frac{\left(f\left(x_{n}\right)+f\left(y_{n}\right)\right) f\left(x_{n}\right) f\left(y_{n}\right)}{f^{\prime}\left(x_{n}\right)\left(f\left(x_{n}\right)^{2}+f\left(y_{n}\right)^{2}\right)} .
$$

Metode iterasi ketiga merupakan metode Newton-Steffensen sebagai berikut

$$
x_{n+1}=x_{n}-\frac{f\left(x_{n}\right)^{2}}{f^{\prime}\left(x_{n}\right)\left(f\left(x_{n}\right)-f\left(y_{n}\right)\right)}
$$

Untuk mengkontruksi metode iterasi dua langkah yang baru dilakukan dengan menjumlahkan metode iterasi pada (13), (15) dan (16) secara linear sebagaimana dilakukan oleh Chun (2007), Jisheng (2007) dan Ezatti dkk (2011) dengan melibatkan tiga parameter real $\theta_{1}, \theta_{2}$ dan $\theta_{3}$ dalam bentuk

$$
\begin{aligned}
x_{n+1}= & \theta_{1}\left(x_{n}-\frac{2 f\left(x_{n}\right)+f\left(y_{n}\right)}{2 f^{\prime}\left(x_{n}\right)}-\frac{1}{2} \frac{f\left(x_{n}\right) f\left(y_{n}\right)}{\left(f\left(x_{n}\right)-f\left(y_{n}\right)\right) f^{\prime}\left(x_{n}\right)}\right) \\
& +\theta_{2}\left(x_{n}-\frac{f\left(x_{n}\right)}{f^{\prime}\left(x_{n}\right)}-\frac{\left(f\left(x_{n}\right)+f\left(y_{n}\right)\right) f\left(x_{n}\right) f\left(y_{n}\right)}{f^{\prime}\left(x_{n}\right)\left(f\left(x_{n}\right)^{2}+f\left(y_{n}\right)^{2}\right)}\right)+\theta_{3}\left(x_{n}-\frac{f\left(x_{n}\right)^{2}}{f^{\prime}\left(x_{n}\right)\left(f\left(x_{n}\right)-f\left(y_{n}\right)\right)}\right)
\end{aligned}
$$

Kemudian Persamaan (17) disederhanakan, maka metode iterasi dua langkah secara lengkap ditulis menjadi 


$$
\begin{aligned}
y_{n}= & x_{n}-\frac{f\left(x_{n}\right)}{f^{\prime}\left(x_{n}\right)}, \\
x_{n+1}= & \left(\theta_{1}+\theta_{2}+\theta_{3}\right) x_{n}-\theta_{1} \frac{f\left(y_{n}\right)}{2 f^{\prime}\left(x_{n}\right)} \\
& -\left(\theta_{1}+\theta_{2}+\frac{\theta_{1} f\left(y_{n}\right)+2 \theta_{3} f\left(x_{n}\right)}{2\left(f\left(x_{n}\right)-f\left(y_{n}\right)\right)}+\frac{\theta_{2} f\left(y_{n}\right)\left(f\left(x_{n}\right)+f\left(y_{n}\right)\right)}{f\left(x_{n}\right)^{2}+f\left(y_{n}\right)^{2}}\right) \frac{f\left(x_{n}\right)}{f^{\prime}\left(x_{n}\right)} .
\end{aligned}
$$

\subsection{Orde Konvergensi}

Sebuah metode dikatakan baik bila metode tersebut efektif. Keefektifan metode dilihat dari indeks effisiensinya dan semakin tinggi orde konvergensi, maka semakin baik pula metode tersebut dalam menghampiri akar-akar suatu persamaan. Untuk menentukan orde konvergensi iterasi dua langkah dengan kombinasi linier tiga metode akan dijelaskan oleh teorema sebagai berikut:

Teorema 1: Asumsikan $\alpha \in D$ adalah akar dari fungsi $f(x)$ yang terdiferensial $f: D \rightarrow R$ pada interval terbuka $D$. Jika $x_{0}$ cukup dekat ke $\alpha$, maka Persamaan (18) mempunyai orde konvergensi empat untuk $\theta_{1}=-2$, $\theta_{2}=3-\theta_{3}$ dan $\theta_{3} \in \mathbb{R}$ dengan persamaan galat berikut

$$
e_{n+1}=\left(-c_{2} c_{3}+7 c_{2}^{3} \theta_{3}\right) e_{n}^{4}+O\left(e_{n}^{5}\right) \text {. }
$$

Bukti: Misalkan $\alpha$ adalah akar persamaan nonlinear $f(x)$, maka $f(\alpha)=0$. Asumsikan $f^{\prime}(x) \neq 0$ dan $x_{n}=\alpha+e_{n}$. Selanjutnya, diaproksimasikan fungsi $f(x)$ disekitar $\alpha$ dengan menggunakan deret Taylor, sehingga diperoleh:

$$
f\left(x_{n}\right)=f^{\prime}(\alpha)\left(e_{n}+c_{2} e_{n}^{2}+c_{3} e_{n}^{3}+O\left(e_{n}^{4}\right)\right),
$$

dengan

$$
c_{j}=\left(\frac{1}{j !}\right) \frac{f^{(j)}(\alpha)}{f^{\prime}(\alpha)}, j=2,3, \ldots,
$$

dan

$$
f^{\prime}\left(x_{n}\right)=f^{\prime}(\alpha)\left(1+2 c_{2} e_{n}+3 c_{3} e_{n}^{2}+O\left(e_{n}^{3}\right)\right) .
$$

Jika Persamaan (20) dibagi dengan Persamaan (22), maka diperoleh:

$$
\frac{f\left(x_{n}\right)}{f^{\prime}\left(x_{n}\right)}=e_{n}-c_{2} e_{n}^{2}+\left(2 c_{3}-2 c_{2}^{2}\right) e_{n}^{3}+O\left(e_{n}^{4}\right) .
$$

Substitusikan Persamaan (23) ke Persamaan (18a), dan oleh karena $x_{n}=e_{n}+\alpha$, Persamaan (18a) dapat ditulis 


$$
y_{n}=\alpha+c_{2} e_{n}^{2}-\left(2 c_{3}-2 c_{2}^{2}\right) e_{n}^{3}+\left(-7 c_{2} c_{3}+3 c_{4}+4 c_{2}^{3}\right) e_{n}^{4}+O\left(e_{n}^{5}\right) .
$$

Ekspansi deret Taylor disekitar $\alpha$ terhadap $f\left(y_{n}\right)$ diberikan oleh

$$
f\left(y_{n}\right)=f^{\prime}(\alpha)\left(c_{2} e_{n}^{2}+\left(2 c_{3}-2 c_{2}^{2}\right) e_{n}^{3}+\left(-7 c_{2} c_{3}+3 c_{4}+4 c_{2}^{3}\right) e_{n}^{4}+O\left(e_{n}^{5}\right)\right),
$$

dan kuadrat dari (20) dan (25), masing-masing diberikan oleh

$$
f\left(x_{n}\right)^{2}=f^{\prime}(\alpha)^{2}\left(e_{n}^{2}+2 c_{2} e_{n}^{3}+\left(c_{2}^{2}+2 c_{3}\right) e_{n}^{4}+O\left(e_{n}^{5}\right)\right)
$$

dan

$$
f\left(y_{n}\right)^{2}=f^{\prime}(\alpha)^{2}\left(c_{2}^{2} e_{n}^{4}+\left(4 c_{2} c_{3}-4 c_{2}^{3}\right) e_{n}^{5}+O\left(e_{n}^{6}\right)\right)
$$

Selanjutnya, gunakan (24), (26), (29), (30) dan (31) memberikan,

$$
\begin{aligned}
& \frac{f\left(y_{n}\right)}{f^{\prime}\left(x_{n}\right)}=c_{2} e_{n}^{2}+\left(2 c_{3}-2 c_{2}^{2}\right) e_{n}^{3}+\left(13 c_{2}^{3}-14 c_{2} c_{3}+3 c_{4}\right) e_{n}^{4}+O\left(e_{n}^{5}\right), \\
& \begin{aligned}
& \frac{\theta_{1} f\left(y_{n}\right)+2 \theta_{3} f\left(x_{n}\right)}{2\left(f\left(x_{n}\right)-f\left(y_{n}\right)\right)}= \theta_{3}+\frac{1}{2}\left(\left(\theta_{1}+2 \theta_{3}\right) c_{2} e_{n}+\left(\theta_{1}+2 \theta_{3}\right)\left(c_{3}-c_{2}^{2}\right) e_{n}^{2}\right. \\
&+ \frac{3}{2}\left(\theta_{1}+2 \theta_{3}\right)\left(c_{2}^{2}-2 c_{2} c_{3}+c_{4}\right) e_{n}^{3}+\cdots+O\left(e_{n}^{5}\right), \\
& \frac{\theta_{2} f\left(y_{n}\right)\left(f\left(x_{n}\right)+f\left(y_{n}\right)\right)}{f\left(x_{n}\right)^{2}+f\left(y_{n}\right)^{2}}= \theta_{2} c_{2} e_{n}-2 \theta_{2}\left(c_{2}^{2}-c_{3}\right) e_{n}^{2}+\theta_{2}\left(c_{2}^{3}-6 c_{2} c_{3}+3 c_{4}\right) e_{n}^{3} \\
&+\cdots+O\left(e_{n}^{5}\right)
\end{aligned}
\end{aligned}
$$

Substitusikan (28), (29), (33), dan (30), maka diperoleh

$$
\begin{aligned}
-\theta_{1} \frac{f\left(y_{n}\right)}{2 f^{\prime}\left(x_{n}\right)}- & \left(\theta_{1}+\theta_{2}+\frac{\theta_{1} f\left(y_{n}\right)+2 \theta_{3} f\left(x_{n}\right)}{2\left(f\left(x_{n}\right)-f\left(y_{n}\right)\right)}+\frac{\theta_{2} f\left(y_{n}\right)\left(f\left(x_{n}\right)+f\left(y_{n}\right)\right)}{f\left(x_{n}\right)^{2}+f\left(y_{n}\right)^{2}}\right) \frac{f\left(x_{n}\right)}{f^{\prime}\left(x_{n}\right)} \\
= & \left(\theta_{1}+\theta_{2}+\theta_{3}\right) e_{n}-\frac{1}{2}\left(3 \theta_{1}+2 \theta_{2}+2 \theta_{3}\right) c_{2}^{2} e_{n}^{3} \\
& +\left(\left(6 \theta_{1}+\theta_{2}+3 \theta_{3}\right) c_{2}^{3}-\left(5 \theta_{1}+3 \theta_{2}+3 \theta_{3}\right) c_{2} c_{3}\right) e_{n}^{4}+O\left(e_{n}^{5}\right)
\end{aligned}
$$

Langkah selanjutnya substitusikan Persamaan (31) ke Persamaan (18), dan dengan menggunakan $x_{n+1}=e_{n+1}+\alpha$, maka diperoleh orde konvergensi dari (22) sebagai berikut

$$
\begin{aligned}
e_{n+1}= & \left(\theta_{1}+\theta_{2}+\theta_{3}-1\right) \alpha+\frac{1}{2}\left(3 \theta_{1}+2 \theta_{2}+2 \theta_{3}\right) c_{2}^{2} e_{n}^{3} \\
& -\left(\left(6 \theta_{1}+\theta_{2}+3 \theta_{3}\right) c_{2}^{3}-\left(5 \theta_{1}+3 \theta_{2}+3 \theta_{3}\right) c_{2} c_{3}\right) e_{n}^{4}+O\left(e_{n}^{5}\right)
\end{aligned}
$$

Persamaan (32) merupakan galat metode iterasi (18), dan sekaligus memberikan informasi bahwa orde konvergensi (18) dapat ditingkatkan dengan mengambil 


$$
\begin{aligned}
& \theta_{1}+\theta_{2}+\theta_{3}-1=0 \\
& 3 \theta_{1}+2 \theta_{2}+2 \theta_{3}=0
\end{aligned}
$$

Oleh karena itu, dengan menyelesaikan (33), diperoleh $\theta_{1}=-2$ dan $\theta_{2}=3-\theta_{3}, \theta_{3} \in \square$. Selanjutnya, dengan mensubstitusikan kembali $\theta_{1}=-2$ dan $\theta_{2}=3-\theta_{3}$ ke (36), diperoleh

$$
e_{n+1}=\left(\left(9-\theta_{3}\right) c_{2}^{3}+c_{2} c_{3}\right) e_{n}^{4}+O\left(e_{n}^{5}\right)
$$

Persamaan (37) memberikan beberapa kemungkinan munculnya metodemetode iterasi baru berode konvergensi empat dengan mengambil sembarang nilai $\theta_{3} \in \square$.

Untuk $\theta_{3}=3$, maka $\theta_{2}=0$ dan $\theta_{1}=-2$,

$$
x_{n+1}=x_{n}-\frac{f\left(x_{n}\right)^{2}+f\left(y_{n}\right)^{2}}{\left(f\left(x_{n}\right)-f\left(y_{n}\right)\right) f^{\prime}\left(x_{n}\right)}
$$

Untuk $\theta_{3}=0$, maka $\theta_{2}=3$ dan $\theta_{1}=-2$,

$$
x_{n+1}=x_{n}-\frac{\left(f\left(x_{n}\right)^{2}+f\left(y_{n}\right)^{2}\right)^{2}-6 f\left(x_{n}\right) f\left(y_{n}\right)^{3}}{\left(f\left(x_{n}\right)^{2}+f\left(y_{n}\right)^{2}\right)\left(f\left(x_{n}\right)-f\left(y_{n}\right)\right) f^{\prime}\left(x_{n}\right)}
$$

\subsection{Simulasi Numerik}

Simulasi numerik dilakukan untuk menguji performa metode iterasi kombinasi tiga metode pada (18) yang disingkat KTLM, kemudian dibandingkan dengan metode iterasi lainnya, seperti: metode Newton yang disingkat MN (Traub (1964)), metode Potra-Ptak disingkat MPP (Potra dan Ptak (1994)), dan metode Chebyshev disingkat MC3 (Kanwar dkk (2008)).

Pada simulasi numerik ini, perhitungan komputasi dilakukan menggunakan software Maple 13 dengan ketelitian 850 angka dibelakang koma. Adapun fungsi-fungsi real yang digunakan sebagai berikut

$$
\begin{aligned}
& f_{1}(x)=x e^{-x}-0,1, \alpha=0,111832559158962, \\
& f_{2}(x)=e^{x}-4 x^{2}, \alpha=4,306584728220692, \\
& f_{3}(x)=\cos (x)-x, \alpha=0,739085133215160, \\
& f_{4}(x)=(x-1)^{3}-1, \alpha=2,0000000000000000, \\
& f_{5}(x)=x^{3}+4 x^{2}-10, \alpha=1,365230034140968,
\end{aligned}
$$




$$
\begin{aligned}
& f_{6}(x)=e^{-x^{2}+x+2}-\cos (x+1)+x^{3}+1, \alpha=-1,0000000000000000, \\
& f_{7}(x)=\sin ^{2}(x)-x^{2}+1, \alpha=1,404491648215341, \\
& f_{8}(x)=\sqrt{x}-x, \alpha=1,0000000000000000 .
\end{aligned}
$$

Untuk membatasi perhitungan komputasi pada saat menentukan jumlah iterasi dan COC, maka penghentian komputasi dilakukan jika memenuhi kriteria $\left|x_{n+1}-x_{n}\right|<\varepsilon$, dengan $\varepsilon=10^{-95}$.

Jumlah iterasi dan orde konvergensi yang dihitung secara komputasi atau computational order of convergence (COC), yang mana nilai-nilai COC ditampilkan dalam kurung, diberikan pada Tabel 1.

Tabel 1 Jumlah Iterasi dan COC dengan $\varepsilon=10^{-95}$

Tabel

\begin{tabular}{rrrrrc}
\hline$f(x)$ & \multicolumn{1}{c}{$x_{0}$} & MN & MPP & MC3 & KLTM \\
\hline \multirow{2}{*}{$f_{1}(x)$} & $-0,20$ & $8(2,0000)$ & $5(3,0000)$ & $5(3,0000)$ & $5(4,0000)$ \\
& 0,20 & $7(2,0000)$ & $5(3,0000)$ & $5(3,0000)$ & $4(4,0000)$ \\
\hline \multirow{2}{*}{$f_{2}(x)$} & 4,10 & $8(2,0000)$ & $5(3,0000)$ & $5(3,0000)$ & $4(4,0000)$ \\
& 4,50 & $7(2,0000)$ & $5(3,0000)$ & $5(3,0000)$ & $4(4,0000)$ \\
\hline \multirow{2}{*}{$f_{3}(x)$} & 0,20 & $7(2,0000)$ & $5(3,0000)$ & $5(3,0000)$ & $4(4,0000)$ \\
& 1,50 & $7(2,0000)$ & $5(3,0000)$ & $5(3,0000)$ & $4(4,0000)$ \\
\hline \multirow{2}{*}{$f_{4}(x)$} & 1,85 & $7(2,0000)$ & $5(3,0000)$ & $5(3,0000)$ & $4(4,0000)$ \\
& 3,00 & $9(2,0000)$ & $6(3,0000)$ & $6(3,0000)$ & $5(4,0000)$ \\
\hline \multirow{2}{*}{$f_{5}(x)$} & 1,05 & $7(2,0000)$ & $5(3,0000)$ & $5(3,0000)$ & $4(4,0000)$ \\
& 2,00 & $8(2,0000)$ & $5(3,0000)$ & $5(3,0000)$ & $4(4,0000)$ \\
\hline \multirow{2}{*}{$f_{6}(x)$} & $-1,50$ & $7(2,0000)$ & $5(3,0000)$ & $5(3,0000)$ & $4(4,0000)$ \\
& 0,00 & $7(2,0000)$ & $5(3,0000)$ & $6(3,0000)$ & $4(4,0000)$ \\
\hline \multirow{2}{*}{$f_{7}(x)$} & 1,20 & $8(2,0000)$ & $5(3,0000)$ & $5(3,0000)$ & $4(4,0000)$ \\
& 2,00 & $8(2,0000)$ & $5(3,0000)$ & $5(3,0000)$ & $5(4,0000)$ \\
\hline \multirow{2}{*}{$f_{8}(x)$} & 0,50 & $8(2,0000)$ & $6(3,0000)$ & $5(3,0000)$ & $5(4,0000)$ \\
& 1,50 & $7(2,0000)$ & $5(3,0000)$ & $5(3,0000)$ & $4(4,0000)$ \\
\hline
\end{tabular}

menunjukkan bahwa metode modifikasi kombinasi linear tiga metode (KLTM 4) dengan $\theta_{1}=-2$ lebih baik dari empat metode lainnya, karena memiliki jumlah iterasi yang lebih sedikit. Selain itu, berdasarkan nilai COC dapat dilihat bahwa metode KLTM 4 memiliki orde konvergensi empat.

Selanjutnya akurasi suatu metode iterasi dapat dilihat dari galat relatif yang dihasilkan pada iterasi tertentu. Pada kasus ini, galat relatif yang dibandingkan berdasarkan jumlah total evaluasi fungsi (total number of functional evaluations (TNFE)) dari setiap metode iterasi yaitu sebesar 12 evaluasi fungsi. 
Tabel 2 Perbandingan $\left|x_{\mathrm{n}+1}-x_{\mathrm{n}}\right|$ dengan TNFE $=12$

\begin{tabular}{|c|c|c|c|c|c|}
\hline$f(x)$ & $x_{0}$ & $\mathrm{MN}$ & MPP & MC3 & KLTM \\
\hline \multirow[t]{2}{*}{$f_{1}(x)$} & $-0,2$ & 1,9116 e-18 & 6,3799 e-13 & 8,4084 e-19 & 2,7239 e-24 \\
\hline & 0,2 & 5,6333 e-33 & 1,7349 e-23 & 8,5741 e-32 & $6,4421 \mathrm{e}-46$ \\
\hline \multirow[t]{2}{*}{$f_{2}(x)$} & 4,1 & 9,0319 e-24 & 4,8779 e-15 & 9,3630 e-24 & 1,5545 e-25 \\
\hline & 4,5 & 3,1056 e-27 & 8,0426 e-20 & 3,2560 e- 26 & 1,1948 e-39 \\
\hline \multirow[t]{2}{*}{$f_{3}(x)$} & 0,2 & 3,2353 e-26 & 1,6335 e-16 & 7,3324 e-19 & 7,0521 e-28 \\
\hline & 1,5 & 3,1900 e-32 & 3,4209 e- 24 & 1,8100 e-17 & 4,0399 e-46 \\
\hline \multirow[t]{2}{*}{$f_{4}(x)$} & 1,8 & 1,0761 e-25 & 8,3877 e-17 & 2,1303 e-24 & 1,8822 e-29 \\
\hline & 3,0 & 1,2443 e-08 & 9,8992 e-06 & 1,4729 e- 08 & 2,0832 e-09 \\
\hline \multirow[t]{2}{*}{$f_{5}(x)$} & 1,0 & 1,0601 e-24 & 8,5214 e-16 & 1,0587 e-22 & 2,6344 e-27 \\
\hline & 2,0 & 1,2356 e-19 & 7,9625 e- 14 & 5,3942 e-18 & 1,5418 e-26 \\
\hline \multirow[t]{2}{*}{$f_{6}(x)$} & $-1,5$ & 2,3956 e-33 & 1,7040 e-24 & 4,0291 e-15 & 3,9356 e-54 \\
\hline & 0,0 & 4,3887 e-33 & 8,0288 e-23 & 3,0145 e-09 & 5,1225 e-40 \\
\hline \multirow[t]{2}{*}{$f_{7}(x)$} & 1,2 & 3,2750 e- 24 & 2,8373 e-15 & 4,9165 e-22 & 1,0632 e-25 \\
\hline & 2,0 & 1,0784 e-16 & 1,0430 e-11 & 1,8755 e-13 & 1,3077 e-21 \\
\hline \multirow[t]{2}{*}{$f_{8}(x)$} & 0,5 & $1,1132 \mathrm{e}-21$ & 9,7033 e-11 & 1,4681 e-11 & 2,7470 e-25 \\
\hline & 1,5 & 2,9188 e-33 & 5,9617 e-25 & 2,8685 e-22 & 1,1527 e-49 \\
\hline
\end{tabular}

Tabel 2, mennjukkan perbandingan galat relatif dari metode-metode iterasi yang dibandingkan. Berdasarkan Tabel 2, dapat dilihat bahwa akurasi metode KTLM secara umum lebih baik dibandingkan dengan metode Newton, metode Potra-Ptak, dan metode Chebyshev.

\section{Simpulan}

Pada artikel ini, metode iterasi baru dikontruksi dengan menggunakan combinasi linear tiga parameter real $\theta_{1}, \theta_{2}$ dan $\theta_{3}$ yang melibatkan tiga evaluasi fungsi yaitu yaitu $f\left(x_{n}\right), f\left(y_{n}\right)$ dan $f^{\prime}\left(x_{n}\right)$. Order konvergensi metode iterasi dua langkah menjadi optimal ketika $\theta_{1}=-2, \theta_{2}=3-\theta_{3}$, dan $\theta_{3} \in \mathbb{R}$ Dengan demikian, metode ini memiliki indeks efisiensi $4^{\frac{1}{3}} \approx 1,5874$ yang mana lebih baik jika dibandingan metode Newton $2^{\frac{1}{2}} \approx 1,4142$, metode PotraPtak $3^{\frac{1}{3}} \approx 1,4422$, metode Chebyshev $3^{\frac{1}{3}} \approx 1,4422$. Secara umum, metode iterasi baru lebih baik dibandingkan dengan metode-metode iterasi lainnya.

Selanjutnya, metode terasi baru dapat dikembangkan orde konvergensinya dengan mengubahnya menjadi metode iterasi tiga langkah. 


\section{Daftar Pustaka}

Chapra, S. C., dan Canale, R. P., 1998, Numerical Methods for Engineers: with Programming and Software Applications, McGraw-Hill, New York.

Chun, C., 2006, Construction of Newton Like Iteration Methods for Solving Nonlinear Equations, Numerische Mathematik, 104, 297-315.

Chun, C., 2007, A Family of Composite Fourth-Order Iterative Methods for Solving Nonlinear Equations, Applied Mathematics and Computation, 187(2), 951-956.

Chun, C., 2008, A Simply Constructed Third-Order Modifications of Newton's Method, Mathematics and Computation, 219, 81-89.

Ezzati, R., dan Saleki, F., 2011, On the Contruction of New Iterative Methods with Fourth-Order Convergence by Combining Previous Methods, International Mathematical Forum, 6 (27), 1319-1326.

Jisheng, K., Yitian, L., dan Xiuhua, W., 2007, A Composite Fourth-Order Iterative Method for Solving Nonlinear Equations, Applied Mathematics and Computation, 184, 471-475.

Kanwar,V., Singh, S., dan Bakshi, S., 2008, Simple geometric constructions of quadratically and cubically convergent iterative functions to solve nonlinear equations, Numerical Algorithm, 47, 95-107.

Kung, H. T dan Traub, J.F., 1974, Optimal order of one-point and multi-point iteration, Applied Mathematics and Computation, 21, 643-651.

Potra, F. A., dan Ptak, V., 1984, Nondiscrete introduction and iterative processes, Research note in Mathematics, 103, Pitman Boston.

Sharma, J. R., 2005, A Composite Third Order Newton-Steffensen Method for Solving Nonlinear Equations, Applied Mathematics and Computation, 169, 242-246.

Traub, J. F., 1964, Iterative Methods for the Solution of Equations, PrentinceHall,Inc., New York. 